\title{
Review Article \\ The Necessity of a Systematic Approach for the Use of MSCs in the Clinical Setting
}

\author{
Christophe Michel Raynaud ${ }^{1}$ and Arash Rafii ${ }^{2,3}$ \\ ${ }^{1}$ Qatar Cardiovascular Research Center, Qatar Foundation, Qatar Science and Technology Park, Doha, Qatar \\ ${ }^{2}$ Department of Genetic Medicine, Weill Cornell Medical College, Doha, Qatar \\ ${ }^{3}$ Stem Cell and Microenvironment Laboratory, Weill Cornell Medical College in Qatar, Education City, Qatar Foundation, \\ Doha, Qatar
}

Correspondence should be addressed to Christophe Michel Raynaud; craynaud@qf.org.qa

Received 21 April 2013; Revised 26 May 2013; Accepted 5 June 2013

Academic Editor: Mohan Vemuri

Copyright (C) 2013 C. M. Raynaud and A. Rafii. This is an open access article distributed under the Creative Commons Attribution License, which permits unrestricted use, distribution, and reproduction in any medium, provided the original work is properly cited.

Cell therapy has emerged as a potential therapeutic strategy in regenerative disease. Among different cell types, mesenchymal stem/stromal cells have been wildly studied in vitro, in vivo in animal models and even used in clinical trials. However, while clinical applications continue to increase markedly, the understanding of their physiological properties and interactions raises many questions and drives the necessity of more caution and supervised strategy in their use.

\section{Introduction}

Since the discovery of pluripotent embryonic stem cells (ESCs) derived from the inner cell mass of blastocysts of embryos, stem cells have been defined by two principal characteristics: self-renewal and ability to differentiate in various cell types. The interest in stem cell use for clinical therapy and regeneration has been growing due to their ability to differentiate into various functional cell types. Among stem cells, two classes can be distinguished: pluripotent stem cells such as embryonic stem cells and induced pluripotent stem cells (IPSCs) [1] and multipotent stem cells with more restricted differentiation capacities, often referred to as adult stem cells. The source of ESCs and the methods used to generate IPSCs [2] together with the risk of teratoma formation [3] raise ethical and safety issues for the clinical use of ESCs and IPSCs [4]. Among adult stem cells, mesenchymal stem/stromal cells (MSCs) are the main seed cells used in regenerative medicine and are an expanding area of research, over the past decade, due to their unique biological properties. These properties cover a large spectrum ranging from immune modulation, local signaling to differentiation abilities. It has been demonstrated in vitro that MSCs can differentiate into osteoblast, chondrocyte, adipocyte, and hepatocytes/cardiomyocytes-like cells. But the use of these cells in numerous preclinical trials raises multiple questions/dilemmas that we will try to address in this review.

(i) Are these cells sufficiently defined and are they true stem cells?

(ii) Should MSCs isolated from different tissues be considered as equivalent?

(iii) What are their major characteristics?

(iv) Can we use them in clinical trials and if so what should be the context?

\section{How Do We Define Mesenchymal Stem Cells?}

2.1. Mesenchymal Stem Cells: Is It Appropriate? Nonhematopoietic cells in the bone marrow were first isolated by Friedenstein et al. in 1968 [5] and defined as spindle-shaped, fibroblast-like multipotent cells capable of colony-forming unit-fibroblast (CFU-F). The studies in the following decade better defined these cells and mainly focused on their abilities to sustain hematopoiesis [6-8]. Pittenger et al. demonstrated 
their in vitro capacity to differentiate into various mesodermal cell types defining them as mesenchymal stem cells [9]. The bone marrow MSCs represent approximately 0,001 to $0,01 \%$ of bone marrow nucleated cells. Therefore, due to the low number of cells and the invasive method required to isolate them, alternative sources of MSCs have been investigated. Cells with similar proprieties have been isolated from a broad range of tissues like skin $[10,11]$, peripheral blood [12], umbilical cord blood [13], muscle [14], adipose tissue [15], placenta [16, 17], dental pulp [18] or liver [19], and others. The differences in isolation protocols and tissues of origin lead to numerous definitions and use of various terms to refer to these cells such as mesenchymal stem cells, mesenchymal progenitor cells, or mesenchymal stromal cells. The confusion in the definition and proprieties of isolated cells prompted the International Society for Cellular Therapy (ISCT) to establish a standard definition of MSCs in 2006 [20]. To qualify as MSCs a cell must have the following characteristics:

(1) plastic adherence;

(2) possess a trilineage differentiation capacity into adipogenic, chondrogenic, and osteogenic cells;

(3) present a surface expression of CD105 (endoglin, END), CD73 (ecto- $5^{\prime}$-nucleotidase), and CD90 (Thyl) and the absence of the hematopoietic markers CD45, CD34, CD14 or CD11b, CD79alpha or CD19, and HLA-DR.

This definition was broadly accepted by the scientific community and allowed more reproducibility between publications. We can underline that these cells were labeled mesenchymal "stromal" cells rather than "stem" cells. At present, MSCs are usually defined as positive for the following markers CD73, CD90, CD105, CD166, CD44, and CD29 and negative for CD14, CD34, CD31, and CD45 [21]. The principal challenge in the definition remains the absence of a single specific marker.

\subsection{Mesenchymal Stem Cells: Stromal Cells or Fibroblast?}

MSC isolation from various sources hinders a precise characterization. In the attempt to better characterize MSCs, most studies have focused on isolation and characterization of surface markers that would define MSCs. The MSCs marker is comprehensively reviewed by Mafi et al. [22]. For example, STRO-1 has been documented as a potential MSCs marker [23] of true multipotent cells. However it appears that while Stro-1 is a robust marker for isolation of such MSCs from tissue like bone marrow, it is not expressed in adipose tissue derived MSCs $[22,24]$. Furthermore, in vitro culture of MSCs induces modification and alteration of surface marker and capacities [22].

It is now broadly accepted that MSCs cultures represent a mix of various cells with various degrees of stemness. Indeed, the "stemness" of MSCs has been previously documented by Lee et al. and Muraglia et al. [25, 26] showing, through limiting dilution, that only some clones displayed multilineage differentiation potential and self-renewal. The rest of the so-called MSCs displayed only limited proliferation potential or partial differentiation ability. The multiclonality of cultured MSCs and their potential modifications is an important factor to consider. Results obtained with MSCs isolated from tissue should be cautiously discussed as few authors actually confirmed rigorously the stemness of the isolated cells.

Another issue is the potential contamination with fibroblasts. The similar shape and the fact that the two cell types share common surface markers are cofounding factors. In a comprehensive review Hematti highlighted that ex vivo culture-expanded MSCs and fibroblasts are indistinguishable by morphology, cell-surface markers, differentiation potential, and immunologic properties [27]. These findings increase the uncertainty of the identity of MSCs. Other than being a semantic debate, this highlights the importance of using the MSCs terminology cautiously. It may be safer, even if not optimal, to refer in most cases to these cell populations as mesenchymal "stromal" cells, as per ISCT definition.

\section{How Different Are MSCs from Different Tissues?}

As mentioned previously, MSCs have been isolated from a broad range of tissues. Following ISCT definition, the necessity to differentiate them into the three main lineages is now a standard for publication. Though, despite the ability to direct differentiation into those different lineages multiple reports demonstrate that their ability to differentiate depends on the tissue origin. For example, we demonstrated that MSCs isolated from bone marrow display around 400 genes differently expressed (at least 2 fold difference) when compared to MSCs isolated from fetal membranes. Their capacity to differentiate (even in the 3 lineages defined by ISCT) is consequently affected by this transcriptional variability [17]. Similarly, numerous publications documented the variable characteristics, differentiation capacities, and therapeutic effects of MSCs isolated from different tissues [28-35]. To explain such differences observed between cells displaying similar phenotype and abilities, multiple theories have been proposed. First, the tissue of origin can induce tissue-specific epigenetic modifications. Indeed, it is easily understandable that in its native organ contexture, an MSC is more likely to differentiate into a certain cell type. This might be pre-determined via chromatin modeling, histone acetylation, methylation, and phosphorylation. The genes involved in the differentiation into a particular cell type can therefore be activated immediately, while forcing this cell into a different cell type requires chromatin remodeling. MSCs isolated from fetal tissues (cord blood, placenta, amniotic membrane, etc...) might be an exception. In this case, the early developmental stage still without tissue-specific epigenetic modification can lead to higher plasticity [32, 34, 36-39].

The studies showing that MSCs from different organs have different properties prompt caution when comparing different preclinical and clinical trials using MSCs. One could advocate for the necessity to develop a panel of standard tests to be used systematically for MSCs characterization in the therapeutic context. Indeed the scientific community 
needs clear standard protocols that will allow increasing reproducibility and ability to compare different studies. This will allow us to meet, in the next decade, the stringent requirements of regulatory authorities.

\section{What Are the Optimal Uses of MSCs?}

4.1. Immunosuppressive Proprieties. One of the most interesting proprieties of MSCs is their immune-modulatory capacity [40-44]. This immune-modulation effect has been extensively studied and reviewed, but certain aspects remain yet to be elucidate [45-49]. As a quick overview, inhibition of TNF-alpha, interferon-gamma, IL-10 and IDO, and nitric oxide production has been proposed to explain the suppression of T-cell proliferation by MSCs $[45,50]$. Similarly, inhibition of B-cell proliferation and differentiation might be caused via similar mechanisms [51]. Besides the inhibition of $\mathrm{B}$ cells and T cells, activation by MSCs of Foxp3+ regulatory T cells was recently proposed [52]. Reduction of IL-1, CD40, and TNF-alpha together with production of prostaglandin E2 (PGE2) was proposed to explain reduction of monocyte and dendritic cell maturation [53]. Finally, NK cells proliferation and cytotoxicity have been demonstrated as inhibited in vitro by MSCs via PEG2 [54].

MSCs have other roles in the immune/inflammatory context. Indeed MSCs were proven to be chemo-attracted to sites of inflammation and to release proinflammatory cytokines [55]. The presence of functional toll-like receptors (TLRs), in particular TLR3 and TLR4 at the surface of MSCs, has been previously well documented. Those TLRs allow the recruitment of MSCs at the site of inflamed and damaged tissues. The TLRs also induce activation of proinflammatory signals and prevent the suppression of T-cell proliferation [56]. This mechanism was proposed to be Notch ligand mediated [56-58].

This bipolarity in MSCs action leads Waterman et al. [58] to propose a paradigm where, in analogy with monocyte/macrophage M1 and M2, MSCs can act as MSC1 type (proinflammatory) or MSC2 type (immunosuppressive). Though, the identification of the factors influencing the balance between those two functions is still yet to be determined.

Overall, the complex multiple mechanisms surrounding the immune-modulation effect of MSCs remain unclear in many aspects and are still being investigated. The multiplicity of interacting immune cells type and the multitude of mechanisms involved necessitate in vivo analysis of the involved mechanisms. Though, the discrepancy between animal and human immune system together with their MSCs differences renders a direct animal/human comparison as difficult.

4.2. Clinical Applications: Diverse Range of Trials for a Broad Range of Proprieties. MSCs have been tested in a wide range of organ traumas or diseases such as liver failure, hematopoietic stem cells (HSCs) implantation, bone trauma, spinal injury, brain trauma, Crohn's disease lesions, immune disease, kidney injury, articular cartilage, and cardiac regeneration $[35,59-65]$.
The rationale of all these trials was based on different properties of MSCs. Nevertheless, all those different characteristics of MSCs are complementary, and the improvements observed are most often the result of these cumulative effects. The various reported effects of MSCs are represented in Figure 1.

4.2.1. Clinical Use of Their Immune-Modulatory Effect. The immune-modulatory effect remains the most intriguing aspect of MSCs biology. This propriety has been widely studied and reviewed [45]. This led to numerous clinical trials for treatment of immune diseases. The main example is for treatment of graft versus host disease (GVHD). Use of MSCs gave promising results in phase 1 and 2 of clinical trials [6668]. Indeed, Le Blanc et al. first transplanted haploidentical MSCs in a child with severe treatment-resistant grade IV. They also documented striking clinical response with a patient 1 year after treatment. Subsequently, Ringdén et al. in 2006 treated eight patients, with steroid-refractory GVHD, with MSCs. Acute GVHD resolved completely in six of eight patients. Complete cure was seen in gut (6 patients), liver (1 patient), and skin (1 patient). Their survival rate was significantly better than control patients [68]. Kebriaei et al. recently reported that out of the 31 patients treated, $94 \%$ showed an initial response to MSCs and 77\% had a complete response.

However, mixed results came out from a larger scale phase III clinical trial including 192 acute GVHD patients [45]. In this study, even if no differences were found with the placebo, an improvement in gastrointestinal and liver outcome of these patients was observed. Nevertheless, the dose and frequency of administration in those GVHD patients were not homogeneous and might have impaired conclusive results.

Similarly, promising results were also obtained in preclinical and clinical phase I trials for Crohn's disease [59]. Duijvestein et al. indicated that autologous bone marrowderived MSCs improve the clinical condition and showed a significant decrease in Crohn's disease activity index, 6 weeks after-treatment in 3 of 10 Crohn's disease patients [59].

In experimental autoimmune encephalomyelitis MSCs injection was reported to improve both condition and histological severity of the disease in multiple trials [69-71]. In multiple sclerosis, disability scale score improvement was observed in 5 patients and stabilization in 1 patient out of 10 included in the trial [72].

The immune-modulatory role of MSCs appears to be of primordial importance in their ability to prevent allograft rejection and was therefore tested in various cell-based therapies. Indeed, their use as immune-modulatory adjuvant to other cell therapies has been broadly tested in various animal models of degenerative diseases [61, 63, 64, 73-75]. Trials for cord blood hematopoietic stem cell engraftment in mice showed that CD45+ cells detected 3 weeks after transplantation were significantly higher in mice cotransplanted with human MSCs. At late time points evaluation (6 weeks) human cells engraftment was higher in the group where MSCs were cotransplanted. Similarly, islets cotransplantation with MSCs in mice demonstrated a significantly lower average blood 


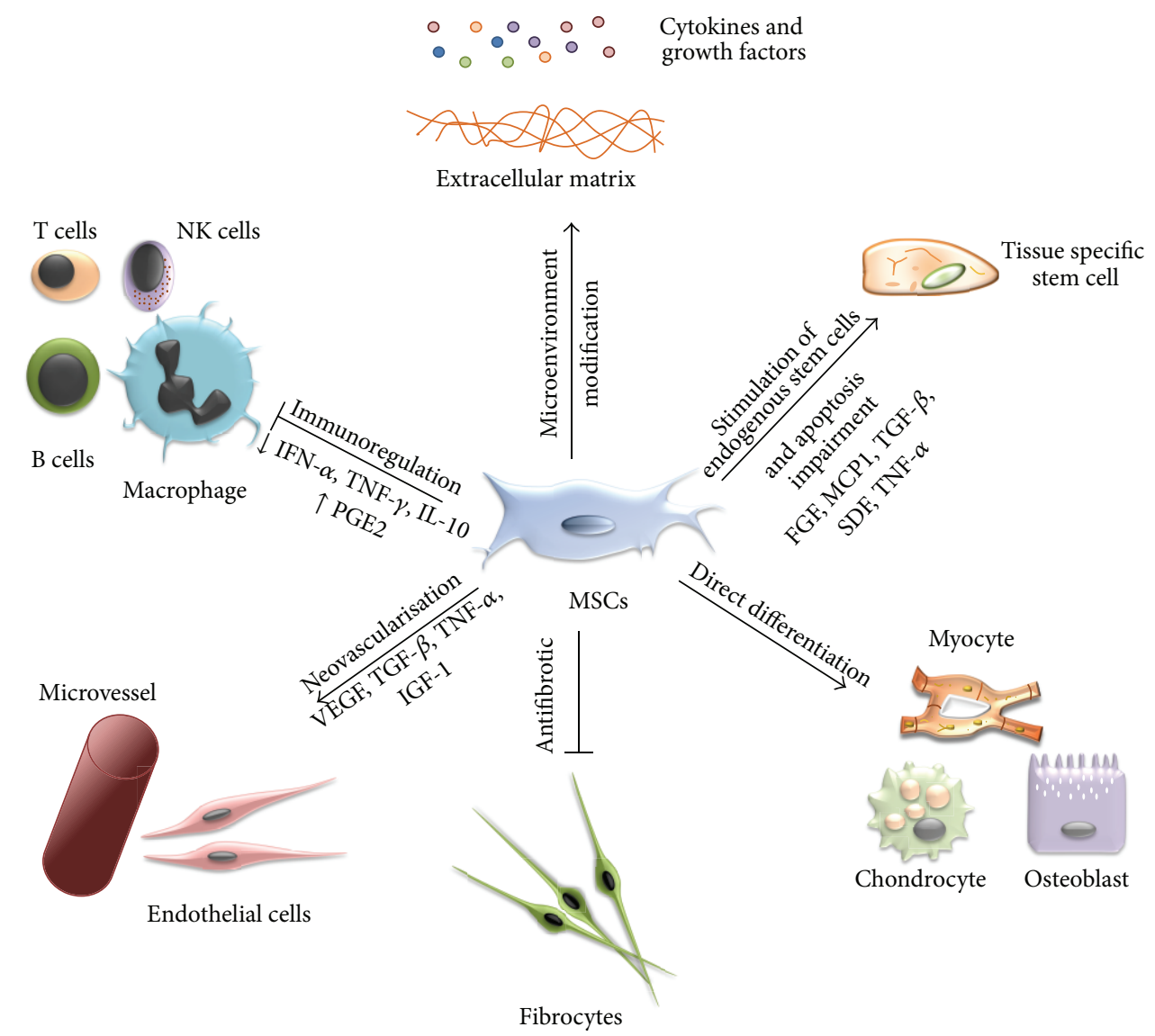

FIGURE 1: MSCs can enhance tissue regeneration via multiple mechanisms.

glucose concentration by 3 weeks. By week $6,71 \%$ of the cotransplanted group was cured compared with $16 \%$ of the islet-alone group. All this work precluded the successful use of MSCs for cotransplantation assays with HSCs in clinical trials to prevent graft rejection [76-78]. For instance, in the first report, Muller et al. showed that a nine-year-old boy transfused with $2 \times 10^{6}$ cells $/ \mathrm{kg}$ of MSC from the same HSCs donor. The patient remained alive and well three years later. Another fourteen-year-old girl received three doses of $0.4 \times 10^{6}$ cells $/ \mathrm{kg}$ before the second HSCs transplant which engrafted properly, and she was disease-free two years later.

4.2.2. Regenerative Potential in the Clinical Setting. The main idea in the clinical use of MSCs remains the potential use of these cells in a regenerative context. Since MSCs were first isolated from bone marrow and their capacity to differentiate into osteoblasts is long known, MSCs turned naturally into a promising candidate in bone defect or trauma repair. Protocols for in vitro culture and differentiation into osteoblast have been perfected. Large bone area defects are usually repaired by scar tissue and often lead to complications such as nonunion. Different clinical trials showed that injection of MSCs alone is not sufficient $[62,79]$. But a combination with scaffold demonstrated better outcomes in animal models and human preclinical trials [80-83]. For instance, four patients with large bone diaphysis defects were transplanted with ceramic scaffolds seeded with autologous bone marrow MSC. Complete fusion between the implant and the host bone was observed 7 months after surgery. All patients demonstrated a good integration of the implants in long-term followup. This study clearly established the advantage of a combined scaffold-cellular therapy as bone engineering approach. Proof of concept was also given when large portion of bones were to be replaced. In a clinical trial, three patients with loss of 4.0$7.0 \mathrm{~cm}$ bone segment were transplanted with MSC-seeded scaffolds. Abundant callus formation and good integration at the interfaces with the host bones were reported using radiography $[81,83]$.

The source of MSCs used played a critical role. In fact, it was demonstrated that MSCs isolated from bone marrow displayed greater capacity towards osteodifferentiation compared to MSCs isolated from adipose tissue $[84,85]$. Similarly, we recently published that MSCs isolated from placenta better responded to osteoactivin (a potential adjuvant for bone reparation) stimulation for osteoblast differentiation than bone marrow derived MSCs [17]. In order to increase osteodifferentiation of injected MSCs, various promising components such as osteoactivin are tested and should be brought to preclinical and clinical trials $[17,86]$.

The other well-characterized ability of MSCs that demonstrates clinical potential is their ability to differentiate into 
chondrocytes. MSCs are used as cellular treatment of cartilage defects $[87,88]$. Preclinical and clinical trials mainly focused on treatment of osteoarthritis with MSCs alone or in combination with scaffolds or other additives [89-97] and demonstrated significant results, with in vivo chondrocyte differentiation of MSCs, motion improvement, pain relief, and promotion of cartilage repair after intra-articular injection [98].

Similarly, in liver failure, in vitro culture medium supplemented with growth factors is able to induce transdifferentiation of MSCs into functional hepatic cells producing albumin and urea with an ability to store glycogen $[60,99]$. Clinical trial using MSCs for the treatment of fulminant hepatic failure, end-stage liver disease, cirrhosis, and inherited metabolic disorders also demonstrated encouraging results with restoration of hepatic function [100-103] and should be brought to larger scale trials.

In vitro and animal studies demonstrated that under an appropriate environment and/or stimulus, MSCs could differentiate into polynucleated myotubes, consistent with a myocyte lineage [104-108]. Animal models showed implantation and differentiation of MSCs in normal or postmyocardial infracted hearts. Successful engraftment was demonstrated by observing the MSCs implantation into scarred myocardium, as well as their expression of $\alpha$-actin, tropomyosin, troponin $\mathrm{T}$, myosin heavy chain, connexin43, GATA-4, and Nkx2.5 [109-111]. Various procedures of administration of MSCs have been tested: intravenous, intracoronary, catheter-based intramyocardial, or direct intramyocardial injection. Based on those results, a broad range of clinical trials were performed for acute myocardial infarction, ischemic cardiomyopathy, or chronic ischemic left ventricular dysfunction [112-115] with marked improvement of cardiac function and patients' outcome. For instance, a randomized double-blind placebo controlled dose escalation study of MSCs administration after acute myocardial infarction in 53 patients demonstrated first the safety of MSCs injection and preliminary efficacy data [114] with reduced ventricular arrhythmias $(P=0.025)$ and improved pulmonary function $(P=0.003)$ in patients receiving MSCs. In a subset analysis, patients with an anterior acute myocardial infarct had improved ventricular function (ejection fraction) compared with the placebo cohort. It seems that more than a direct transdifferentiation into cardiomyocytes, the benefit observed in those studies relied on other MSCs properties.

4.2.3. MSCs Paracrine Effects. It is now accepted that a major indirect effect of MSCs after implantation is related to their so-called paracrine effect. Through a broad spectrum of cytokines and growth factors, MSCs were proposed to drive tissue recovery via stimulation of endogenous stem cells, apoptosis impairment, stimulation of neovascularization, and extracellular matrix modification, together with reduction of fibrosis and scar tissue formation [116-118].

Bone marrow derived MSCs have been described as important actors in HSCs niche in bone marrow [119, 120]. MSCs have been tested as adjuvant to HSCs engraftment.
It is clearly established that cotransplantation of HSCs with MSCs decreases the risk of rejection and increases the longterm repopulation. More than direct interaction with injected HSCs, it is proposed that the large spectrum of released molecules is responsible for acute engraftment [61].

We previously discussed that restoration of hepatic function is achieved following MSCs injection; however, the rate of long-term implantation of the cells is low [121, 122]. Following these results, recent studies demonstrated that MSC-conditioned medium or MSC-derived molecules also demonstrated important positive results comparable to direct MSCs transplantation [102, 123].

Similarly to liver studies, it was demonstrated that MSCs conditioned media could improve cell survival and prognostic when injected into an infracted heart [124]. Additionally, more than direct implantation and differentiation of MSCs, the paracrine effect of MSCs has been postulated to contribute to improve endogenous cell survival, cardiogenesis stimulation of inner progenitor, and neovasculogenesis of infracted regions $[65,117,124-126]$. The scaring process of infracted tissue is tuned down after MSCs injection, most probably due to their capacity of extracellular matrix modification.

\section{Limitations and Caution in Clinical Use of MSCs}

Despite all the promising results published and reporting improvement following MSCs injection in various models, numerous area of uncertainty remains. First of all, data on long-term efficacy are still missing in many contexts. Mostly short-term followup has been published to date, and even long-term rodent studies are by nature limited.

In vitro culture of MSCs previous to all clinical trials engenders different risks. In vitro culture can modify cell characteristics. There is always a risk of viral, bacterial, or primal infections $[127,128]$. Thus the requirement to develop standard procedures within highly regulated GMP laboratories.

Another poorly documented risk with MSCs injection is the migratory potential of MSCs. MSCs have been shown to display significant migration following stimulation with numerous factors such IL8, VEGF, and IGF [129]. For example, a study in rabbits showed that MSCs injected in the articulation could be later found in digestive tractus and thymus [130]. This ectopic implantation of MSCs has been shown to result in bone formation in rodent studies [131, 132]. Finally the inability to control the differentiation potential might lead to complications such as bone differentiation within ectopic tissue such as the heart in preclinical models [133].

Finally, many reports show a fundamental role of MSCs in tumor malignant transformation and progression [134, 135]. It was recently established that, even if limited, long-term culture of MSCs leads to chromosomal aberrations [136, 137] leading to the risk of injection of cells with carcinogenic potential [138]. 


\section{Discussion}

In summary, the past 5 to 10 years have been remarkably active for MSC studies. Even if MSCs are revealed to be a strong tool with various convenient properties and promising potential, additional initiatives should be undertaken to further accelerate the process of enhancing our understanding of MSC biology in vivo. Additionally, appropriately designed clinical trials with multicentric randomized trials should be achieved to clarify results and allow comparison of the various trials leaded. Unlike in animal models, followup of engraftment and MSCs persistence remains complex in human clinical trials and remains the point of focus of multiple technological developments. Creation of trial database with long-term followup would help in monitoring secondary deleterious effect of MSCs administration to patients.

Even if MSCs injection demonstrated encouraging improvement of patient's conditions, where classical treatment fails, monitoring long-term clinical outcome is of primary importance. Finally, acute understanding of molecular mechanism and factors involved in MSCs injection benefice may lead to a safer replacement of MSCs by controlled molecular therapy with similar outcomes.

\section{Acknowledgments}

This work was funded by Qatar Foundation JSREP Grants 3021-3-012 and NPRP 09-1174-3-291. Its contents are solely the responsibility of the authors and do not necessarily represent the official views of the Qatar National Research Fund.

\section{References}

[1] J. Yu, M. A. Vodyanik, K. Smuga-Otto et al., "Induced pluripotent stem cell lines derived from human somatic cells," Science, vol. 318, no. 5858, pp. 1917-1920, 2007.

[2] K. Miura, Y. Okada, T. Aoi et al., "Variation in the safety of induced pluripotent stem cell lines," Nature Biotechnology, vol. 27, no. 8, pp. 743-745, 2009.

[3] I. Gutierrez-Aranda, V. Ramos-Mejia, C. Bueno et al., "Human induced pluripotent stem cells develop teratoma more efficiently and faster than human embryonic stem cells regardless the site of injection," Stem Cells, vol. 28, no. 9, pp. 1568-1570, 2010.

[4] D. W. Fink Jr., "FDA regulation of stem cell-based products," Science, vol. 324, no. 5935, pp. 1662-1663, 2009.

[5] A. J. Friedenstein, K. V. Petrakova, A. I. Kurolesova, and G. P. Frolova, "Heterotopic of bone marrow. Analysis of precursor cells for osteogenic and hematopoietic tissues," Transplantation, vol. 6, no. 2, pp. 230-247, 1968.

[6] T. M. Dexter, T. D. Allen, and L. G. Lajtha, "Conditions controlling the proliferation of haemopoietic stem cells in vitro," Journal of Cellular Physiology, vol. 91, no. 3, pp. 335-344, 1977.

[7] H. Castro-Malaspina, R. E. Gay, and G. Resnick, "Characterization of human bone marrow fibroblast colony-forming cells (CFU-F) and their progeny," Blood, vol. 56, no. 2, pp. 289-301, 1980.

[8] B. R. Clark and A. Keating, "Biology of bone marrow stroma," Annals of the New York Academy of Sciences, vol. 770, pp. 70-78, 1995.
[9] M. F. Pittenger, A. M. Mackay, S. C. Beck et al., "Multilineage potential of adult human mesenchymal stem cells," Science, vol. 284, no. 5411, pp. 143-147, 1999.

[10] U. Riekstina, R. Muceniece, I. Cakstina, I. Muiznieks, and J. Ancans, "Characterization of human skin-derived mesenchymal stem cell proliferation rate in different growth conditions," Cytotechnology, vol. 58, no. 3, pp. 153-162, 2008.

[11] S. T. Hsiao, A. Asgari, Z. Lokmic et al., "Comparative analysis of paracrine factor expression in human adult mesenchymal stem cells derived from bone marrow, adipose, and dermal tissue," Stem Cells and Development, vol. 21, no. 12, pp. 2189-2203, 2012.

[12] J. Lyahyai, D. R. Mediano, B. Ranera et al., "Isolation and characterization of ovine mesenchymal stem cells derived from peripheral blood," BMC Veterinary Research, vol. 8, p. 169, 2012.

[13] A. Erices, P. Conget, and J. J. Minguell, "Mesenchymal progenitor cells in human umbilical cord blood," British Journal of Haematology, vol. 109, no. 1, pp. 235-242, 2000.

[14] H. Peng and J. Huard, "Muscle-derived stem cells for musculoskeletal tissue regeneration and repair," Transplant Immunology, vol. 12, no. 3-4, pp. 311-319, 2004.

[15] Y. Zhu, T. Liu, K. Song, X. Fan, X. Ma, and Z. Cui, "Ex vivo expansion of adipose tissue-derived stem cells in spinner flasks," Biotechnology Journal, vol. 4, no. 8, pp. 1198-1209, 2009.

[16] P. S. In’t Anker, S. A. Scherjon, C. Kleijburg-Van Der Keur et al., "Isolation of mesenchymal stem cells of fetal or maternal origin from human placenta," Stem Cells, vol. 22, no. 7, pp. 1338-1345, 2004.

[17] C. M. Raynaud, M. Maleki, R. Lis et al., "Comprehensive characterization of mesenchymal stem cells from human placenta and fetal membrane and their response to osteoactivin stimulation," Stem Cells International, vol. 2012, Article ID 658356, 13 pages, 2012.

[18] S. Gronthos, M. Mankani, J. Brahim, P. G. Robey, and S. Shi, "Postnatal human dental pulp stem cells (DPSCs) in vitro and in vivo," Proceedings of the National Academy of Sciences of the United States of America, vol. 97, no. 25, pp. 13625-13630, 2000.

[19] C. Campagnoli, I. A. G. Roberts, S. Kumar, P. R. Bennett, I. Bellantuono, and N. M. Fisk, "Identification of mesenchymal stem/progenitor cells in human first-trimester fetal blood, liver, and bone marrow," Blood, vol. 98, no. 8, pp. 2396-2402, 2001.

[20] M. Dominici, K. Le Blanc, I. Mueller et al., "Minimal criteria for defining multipotent mesenchymal stromal cells. The International Society for Cellular Therapy position statement," Cytotherapy, vol. 8, no. 4, pp. 315-317, 2006.

[21] M. E. Bernardo, A. M. Cometa, D. Pagliara et al., "Ex vivo expansion of mesenchymal stromal cells," Best Practice \& Research Clinical Haematology, vol. 24, no. 1, pp. 73-81, 2011.

[22] P. Mafi, S. Hindocha, R. Mafi, M. Griffin, and W. S. Khan, "Adult mesenchymal stem cells and cell surface characterizationa systematic review of the literature," The Open Orthopaedics Journal, vol. 5, supplement 2, pp. 253-260, 2011.

[23] H. Ning, G. Lin, T. F. Lue, and C.-S. Lin, "Mesenchymal stem cell marker Stro-1 is a 75kd endothelial antigen," Biochemical and Biophysical Research Communications, vol. 413, no. 2, pp. 353357, 2011.

[24] M. Tanaka-Douzono, S. Suzu, M. Yamada et al., "Surface protein characterization of human adipose tissue-derived stromal cells," Journal of Cellular Physiology, vol. 189, no. 1, pp. 54-63, 2001.

[25] C. C. I. Lee, J. E. Christensen, M. C. Yoder, and A. F. Tarantal, "Clonal analysis and hierarchy of human bone marrow mesenchymal stem and progenitor cells," Experimental Hematology, vol. 38, no. 1, pp. 46-54, 2010. 
[26] A. Muraglia, R. Cancedda, and R. Quarto, "Clonal mesenchymal progenitors from human bone marrow differentiate in vitro according to a hierarchical model," Journal of Cell Science, vol. 113, no. 7, pp. 1161-1166, 2000.

[27] P. Hematti, "Mesenchymal stromal cells and fibroblasts: a case of mistaken identity?" Cytotherapy, vol. 14, no. 5, pp. 516-521, 2012.

[28] S. L. Lindsay, S. A. Johnstone, J. C. Mountford et al., "Human mesenchymal stem cells isolated from olfactory biopsies but not bone enhance CNS myelination in vitro," Glia, vol. 61, no. 3, pp. 368-382, 2013.

[29] A. A. Ramkisoensing, D. A. Pijnappels, S. F. A. Askar et al., "Human embryonic and fetal Mesenchymal stem cells differentiate toward three different cardiac lineages in contrast to their adult counterparts," PLoS ONE, vol. 6, no. 9, Article ID e24164, 2011.

[30] F. J. Adegani, L. Langroudi, E. Arefian, A. Shafiee, P. Dinarvand, and M. Soleimani, "A comparison of pluripotency and differentiation status of four mesenchymal adult stem cells," Molecular Biology Reports, vol. 40, no. 5, pp. 3693-3703, 2013.

[31] R. I. Dmitrieva, R. Minullina, A. A. Bilibina, O. V. Tarasova, S. V. Anisimov, and A. Y. Zaritskey, "Bone marrow- and subcutaneous adipose tissue-derived mesenchymal stem cells: differences and similarities," Cell Cycle, vol. 11, no. 2, pp. 377$383,2012$.

[32] S. Balasubramanian, P. Venugopal, S. Sundarraj, Z. Zakaria, A. S. Majumdar, and M. Ta, "Comparison of chemokine and receptor gene expression between Wharton's jelly and bone marrow-derived mesenchymal stromal cells," Cytotherapy, vol. 14, no. 1, pp. 26-33, 2012.

[33] R. Hass, C. Kasper, S. Bohm, and R. Jacobs, "Different populations and sources of human mesenchymal stem cells (MSC): a comparison of adult and neonatal tissue-derived MSC," Cell Communication and Signaling, p. 12, 2011.

[34] I. Manini, L. Gulino, B. Gava et al., "Multi-potent progenitors in freshly isolated and cultured human mesenchymal stem cells: a comparison between adipose and dermal tissue," Cell and Tissue Research, vol. 344, no. 1, pp. 85-95, 2011.

[35] Y. Ikegame, K. Yamashita, S.-I. Hayashi et al., "Comparison of mesenchymal stem cells from adipose tissue and bone marrow for ischemic stroke therapy," Cytotherapy, vol. 13, no. 6, pp. 675685, 2011.

[36] M. Strioga, S. Viswanathan, A. Darinskas, O. Slaby, and J. Michalek, "Same or not the same? Comparison of adipose tissue-derived versus bone marrow-derived mesenchymal stem and stromal cells," Stem Cells and Development, vol. 21, no. 14, pp. 2724-2752, 2012.

[37] R. B. Jakobsen, A. Shahdadfar, F. P. Reinholt, and J. E. Brinchmann, "Chondrogenesis in a hyaluronic acid scaffold: comparison between chondrocytes and MSC from bone marrow and adipose tissue," Knee Surgery, Sports Traumatology, Arthroscopy, vol. 18, no. 10, pp. 1407-1416, 2010.

[38] G. Yannarelli, N. Pacienza, L. Cuniberti, J. Medin, J. Davies, and A. Keating, "Brief report: the potential role of epigenetics on multipotent cell differentiation capacity of mesenchymal stromal cells," Stem Cells, vol. 31, no. 1, pp. 215-220, 2013.

[39] C. M. Teven, X. Liu, N. Hu et al., "Epigenetic regulation of mesenchymal stem cells: a focus on osteogenic and adipogenic differentiation," Stem Cells International, vol. 2011, Article ID 201371, 18 pages, 2011.

[40] K. Le Blanc, L. Tammik, B. Sundberg, S. E. Haynesworth, and O. Ringdén, "Mesenchymal stem cells inhibit and stimulate mixed lymphocyte cultures and mitogenic responses independently of the major histocompatibility complex," Scandinavian Journal of Immunology, vol. 57, no. 1, pp. 11-20, 2003.

[41] P. A. Muraro and A. Uccelli, "Immuno-therapeutic potential of haematopoietic and mesenchymal stem cell transplantation in MS," Results and Problems in Cell Differentiation, vol. 51, pp. 237257, 2010.

[42] A. Uccelli, L. Moretta, and V. Pistoia, "Mesenchymal stem cells in health and disease," Nature Reviews Immunology, vol. 8, no. 9, pp. 726-736, 2008.

[43] J. Tolar, K. Le Blanc, A. Keating, and B. R. Blazar, "Concise review: hitting the right spot with mesenchymal stromal cells," Stem Cells, vol. 28, no. 8, pp. 1446-1455, 2010.

[44] K. English, A. French, and K. J. Wood, "Mesenchymal stromal cells: facilitators of successful transplantation?" Cell Stem Cell, vol. 7, no. 4, pp. 431-442, 2010.

[45] T. Yi and S. U. Song, "Immunomodulatory properties of mesenchymal stem cells and their therapeutic applications," Archives of Pharmacal Research, vol. 35, no. 2, pp. 213-221, 2012.

[46] E. Soleymaninejadian, K. Pramanik, and E. Samadian, "Immunomodulatory properties of mesenchymal stem cells: cytokines and factors," American Journal of Reproductive Immunology, vol. 67, no. 1, pp. 1-8, 2012.

[47] P.-M. Chen, M.-L. Yen, K.-J. Liu, H.-K. Sytwu, and B.-L. Yen, "Immunomodulatory properties of human adult and fetal multipotent mesenchymal stem cells," Journal of Biomedical Science, vol. 18, no. 1, article 49, 2011.

[48] B. R. Weil, M. C. Manukyan, J. L. Herrmann et al., "The immunomodulatory properties of mesenchymal stem cells: implications for surgical disease," Journal of Surgical Research, vol. 167, no. 1, pp. 78-86, 2011.

[49] M. J. Hoogduijn, F. Popp, R. Verbeek et al., "The immunomodulatory properties of mesenchymal stem cells and their use for immunotherapy," International Immunopharmacology, vol. 10, no. 12, pp. 1496-1500, 2010.

[50] R. Abdi, P. Fiorina, C. N. Adra, M. Atkinson, and M. H. Sayegh, "Immunomodulation by mesenchymal stem cells: a potential therapeutic strategy for type 1 diabetes," Diabetes, vol. 57, no. 7, pp. 1759-1767, 2008.

[51] S. S. Iyer and M. Rojas, "Anti-inflammatory effects of mesenchymal stem cells: novel concept for future therapies," Expert Opinion on Biological Therapy, vol. 8, no. 5, pp. 569-581, 2008.

[52] K. H. Jung, S. U. Song, T. Yi et al., "Human bone marrowderived clonal mesenchymal stem cells inhibit inflammation and reduce acute pancreatitis in rats," Gastroenterology, vol. 140, no. 3, pp. 998-1008, 2011.

[53] G. M. Spaggiari, H. Abdelrazik, F. Becchetti, and L. Moretta, "MSCs inhibit monocyte-derived DC maturation and function by selectively interfering with the generation of immature DCs: central role of MSC-derived prostaglandin E2," Blood, vol. 113, no. 26, pp. 6576-6583, 2009.

[54] G. M. Spaggiari, A. Capobianco, H. Abdelrazik, F. Becchetti, M. C. Mingari, and L. Moretta, "Mesenchymal stem cells inhibit natural killer-cell proliferation, cytotoxicity, and cytokine production: role of indoleamine 2,3-dioxygenase and prostaglandin E2," Blood, vol. 111, no. 3, pp. 1327-1333, 2008.

[55] G. Ren, L. Zhang, X. Zhao et al., "Mesenchymal stem cellmediated immunosuppression occurs via concerted action of chemokines and nitric oxide," Cell Stem Cell, vol. 2, no. 2, pp. 141-150, 2008. 
[56] F. Liotta, R. Angeli, L. Cosmi et al., "Toll-like receptors 3 and 4 are expressed by human bone marrow-derived mesenchymal stem cells and can inhibit their T-cell modulatory activity by impairing notch signaling," Stem Cells, vol. 26, no. 1, pp. 279289, 2008.

[57] S. L. Tomchuck, K. J. Zwezdaryk, S. B. Coffelt, R. S. Waterman, E. S. Danka, and A. B. Scandurro, "Toll-like receptors on human mesenchymal stem cells drive their migration and immunomodulating responses," Stem Cells, vol. 26, no. 1, pp. 99-107, 2008.

[58] R. S. Waterman, S. L. Tomchuck, S. L. Henkle, and A. M. Betancourt, "A new mesenchymal stem cell (MSC) paradigm: polarization into a pro-inflammatory $\mathrm{MSC1}$ or an immunosuppressive MSC2 phenotype," PLoS ONE, vol. 5, no. 4, Article ID e10088, 2010.

[59] M. Duijvestein, A. C. W. Vos, H. Roelofs et al., "Autologous bone marrow-derived mesenchymal stromal cell treatment for refractory luminal Crohn's disease: results of a phase I study," Gut, vol. 59, no. 12, pp. 1662-1669, 2010.

[60] R. Taléns-Visconti, A. Bonora, R. Jover et al., "Hepatogenic differentiation of human mesenchymal stem cells from adipose tissue in comparison with bone marrow mesenchymal stem cells," World Journal of Gastroenterology, vol. 12, no. 36, pp. 5834-5845, 2006.

[61] S. Carrancio, C. Romo, T. Ramos et al., "Effects of MSC-coadministration and route of delivery on cord blood hematopoietic stem cell engraftment," Cell Transplant, 2012.

[62] A. Hofmann, U. Ritz, M. H. Hessmann et al., "Cell viability, osteoblast differentiation, and gene expression are altered in human osteoblasts from hypertrophic fracture non-unions," Bone, vol. 42, no. 5, pp. 894-906, 2008.

[63] T. Amemori, P. Jendelová, K. Růžičková, D. Arboleda, and E. Syková, "Co-transplantation of olfactory ensheathing glia and mesenchymal stromal cells does not have synergistic effects after spinal cord injury in the rat," Cytotherapy, vol. 12, no. 2, pp. 212-225, 2010.

[64] C. L. Rackham, P. C. Chagastelles, N. B. Nardi, A. C. HaugeEvans, P. M. Jones, and A. J. King, "Co-transplantation of islets with mesenchymal stem cells in microcapsules demonstrates graft outcome can be improved in an isolated-graft model of islet transplantation in mice," Cytotherapy, vol. 15, no. 2, pp. 192200, 2011.

[65] F. S. Loffredo, M. L. Steinhauser, J. Gannon, and R. T. Lee, "Bone marrow-derived cell therapy stimulates endogenous cardiomyocyte progenitors and promotes cardiac repair," Cell Stem Cell, vol. 8, no. 4, pp. 389-398, 2011.

[66] P. Kebriaei, L. Isola, E. Bahceci et al., "Adult human mesenchymal stem cells added to corticosteroid therapy for the treatment of acute graft-versus-host disease," Biology of Blood and Marrow Transplantation, vol. 15, no. 7, pp. 804-811, 2009.

[67] K. Le Blanc, I. Rasmusson, B. Sundberg et al., "Treatment of severe acute graft-versus-host disease with third party haploidentical mesenchymal stem cells," The Lancet, vol. 363, no. 9419, pp. 1439-1441, 2004.

[68] O. Ringdén, M. Uzunel, I. Rasmusson et al., "Mesenchymal stem cells for treatment of therapy-resistant graft-versus-host disease," Transplantation, vol. 81, no. 10, pp. 1390-1397, 2006.

[69] E. Zappia, S. Casazza, E. Pedemonte et al., "Mesenchymal stem cells ameliorate experimental autoimmune encephalomyelitis inducing T-cell anergy," Blood, vol. 106, no. 5, pp. 1755-1761, 2005.
[70] M. Rafei, P. M. Campeau, A. Aguilar-Mahecha et al., "Mesenchymal stromal cells ameliorate experimental autoimmune encephalomyelitis by inhibiting CD4 Th17 T cells in a CC chemokine ligand 2-dependent manner," Journal of Immunology, vol. 182, no. 10, pp. 5994-6002, 2009.

[71] G. Constantin, S. Marconi, B. Rossi et al., "Adipose-derived mesenchymal stem cells ameliorate chronic experimental autoimmune encephalomyelitis," Stem Cells, vol. 27, no. 10, pp. 26242635, 2009.

[72] B. Yamout, R. Hourani, H. Salti et al., "Bone marrow mesenchymal stem cell transplantation in patients with multiple sclerosis: a pilot study," Journal of Neuroimmunology, vol. 227, no. 1-2, pp. 185-189, 2010.

[73] B. G. Jaganathan, V. Tisato, T. Vulliamy et al., "Effects of MSC co-injection on the reconstitution of aplastic anemia patient following hematopoietic stem cell transplantation," Leukemia, vol. 24, no. 10, pp. 1791-1795, 2010.

[74] M. Joshi, B. Patil P, Z. He, J. Holgersson, M. Olausson, and S. Sumitran-Holgersson, "Fetal liver-derived mesenchymal stromal cells augment engraftment of transplanted hepatocytes," Cytotherapy, vol. 14, no. 6, pp. 657-669, 2012.

[75] A. V. Vanikar, S. D. Dave, U. G. Thakkar, and H. L. Trivedi, "Cotransplantation of adipose tissue-derived insulin-secreting mesenchymal stem cells and hematopoietic stem cells: a novel therapy for insulin-dependent diabetes mellitus," Stem Cells International, vol. 2010, Article ID 582382, 5 pages, 2010.

[76] I. Müller, S. Kordowich, C. Holzwarth et al., "Application of multipotent mesenchymal stromal cells in pediatric patients following allogeneic stem cell transplantation," Blood Cells, Molecules, and Diseases, vol. 40, no. 1, pp. 25-32, 2008.

[77] S. T. Lee, J. H. Jang, J.-W. Cheong et al., "Treatment of high-risk acute myelogenous leukaemia by myeloablative chemoradiotherapy followed by co-infusion of T cell-depleted haematopoietic stem cells and culture-expanded marrow mesenchymal stem cells from a related donor with one fully mismatched human leucocyte antigen haplotype," British Journal of Haematology, vol. 118, no. 4, pp. 1128-1131, 2002.

[78] L. M. Ball, M. E. Bernardo, H. Roelofs et al., "Cotransplantation of ex vivo-expanded mesenchymal stem cells accelerates lymphocyte recovery and may reduce the risk of graft failure in haploidentical hematopoietic stem-cell transplantation," Blood, vol. 110, no. 7, pp. 2764-2767, 2007.

[79] C. Seebach, D. Henrich, R. Tewksbury, K. Wilhelm, and I. Marzi, "Number and proliferative capacity of human mesenchymal stem cells are modulated positively in multiple trauma patients and negatively in atrophic nonunions," Calcified Tissue International, vol. 80, no. 4, pp. 294-300, 2007.

[80] M. Marcacci, E. Kon, V. Moukhachev et al., "Stem cells associated with macroporous bioceramics for long bone repair: 6- to 7-year outcome of a pilot clinical study," Tissue Engineering, vol. 13, no. 5, pp. 947-955, 2007.

[81] R. Quarto, M. Mastrogiacomo, R. Cancedda et al., "Repair of large bone defects with the use of autologous bone marrow stromal cells," The New England Journal of Medicine, vol. 344, no. 5, pp. 385-386, 2001.

[82] R. Cancedda, B. Dozin, P. Giannoni, and R. Quarto, "Tissue engineering and cell therapy of cartilage and bone," Matrix Biology, vol. 22, no. 1, pp. 81-91, 2003.

[83] E. Kon, A. Muraglia, A. Corsi et al., "Autologous bone marrow stromal cells loaded onto porous hydroxyapatite ceramic accelerate bone repair in critical-size defects of sheep long bones," 
Journal of Biomedical Materials Research, vol. 49, no. 3, pp. 328337, 2000.

[84] G. Pachón-Peña, G. Yu, A. Tucker et al., "Stromal stem cells from adipose tissue and bone marrow of age-matched female donors display distinct immunophenotypic profiles," Journal of Cellular Physiology, vol. 226, no. 3, pp. 843-851, 2011.

[85] A. Shafiee, E. Seyedjafari, M. Soleimani, N. Ahmadbeigi, P. Dinarvand, and N. Ghaemi, "A comparison between osteogenic differentiation of human unrestricted somatic stem cells and mesenchymal stem cells from bone marrow and adipose tissue," Biotechnology Letters, vol. 33, no. 6, pp. 1257-1264, 2011.

[86] C. Scotti, B. Tonnarelli, A. Papadimitropoulos et al., "Recapitulation of endochondral bone formation using human adult mesenchymal stem cells as a paradigm for developmental engineering," Proceedings of the National Academy of Sciences of the United States of America, vol. 107, no. 16, pp. 7251-7256, 2010.

[87] H. Fan, Y. Hu, C. Zhang et al., "Cartilage regeneration using mesenchymal stem cells and a PLGA-gelatin/chondroitin/ hyaluronate hybrid scaffold," Biomaterials, vol. 27, no. 26, pp. 4573-4580, 2006.

[88] L. Zheng, J. Sun, X. Chen et al., "In vivo cartilage engineering with collagen hydrogel and allogenous chondrocytes after diffusion chamber implantation in immunocompetent host," Tissue Engineering Part A, vol. 15, no. 8, pp. 2145-2153, 2009.

[89] M. Agung, M. Ochi, S. Yanada et al., "Mobilization of bone marrow-derived mesenchymal stem cells into the injured tissues after intraarticular injection and their contribution to tissue regeneration," Knee Surgery, Sports Traumatology, Arthroscopy, vol. 14, no. 12, pp. 1307-1314, 2006.

[90] M. Horie, I. Sekiya, T. Muneta et al., "Intra-articular injected synovial stem cells differentiate into meniscal cells directly and promote meniscal regeneration without mobilization to distant organs in rat massive meniscal defect," Stem Cells, vol. 27, no. 4, pp. 878-887, 2009.

[91] J. M. Murphy, D. J. Fink, E. B. Hunziker, and F. P. Barry, "Stem cell therapy in a caprine model of osteoarthritis," Arthritis and Rheumatism, vol. 48, no. 12, pp. 3464-3474, 2003.

[92] D. D. Frisbie, J. D. Kisiday, C. E. Kawcak, N. M. Werpy, and C. W. McIlwraith, "Evaluation of adipose-derived stromal vascular fraction or bone marrow-derived mesenchymal stem cells for treatment of osteoarthritis," Journal of Orthopaedic Research, vol. 27, no. 12, pp. 1675-1680, 2009.

[93] S. Wakitani, K. Imoto, T. Yamamoto, M. Saito, N. Murata, and M. Yoneda, "Human autologous culture expanded bone marrow-mesenchymal cell transplantation for repair of cartilage defects in osteoarthritic knees," Osteoarthritis and Cartilage, vol. 10, no. 3, pp. 199-206, 2002.

[94] C. J. Centeno, D. Busse, J. Kisiday, C. Keohan, M. Freeman, and D. Karli, "Increased knee cartilage volume in degenerative joint disease using percutaneously implanted, autologous mesenchymal stem cells," Pain Physician, vol. 11, no. 3, pp. 343-353, 2008.

[95] F. Davatchi, B. S. Abdollahi, M. Mohyeddin, F. Shahram, and B. Nikbin, "Mesenchymal stem cell therapy for knee osteoarthritis. Preliminary report of four patients," International Journal of Rheumatic Diseases, vol. 14, no. 2, pp. 211-215, 2011.

[96] U. Nöth, A. F. Steinert, and R. S. Tuan, “Technology Insight: adult mesenchymal stem cells for osteoarthritis therapy," Nature Clinical Practice Rheumatology, vol. 4, no. 7, pp. 371-380, 2008.

[97] K. Johnson, S. Zhu, M. S. Tremblay et al., "A stem cell-based approach to cartilage repair," Science, vol.336, no. 6082, pp. 717721, 2012.
[98] Y. Qi, G. Feng, and W. Yan, "Mesenchymal stem cell-based treatment for cartilage defects in osteoarthritis," Molecular Biology Reports, vol. 39, no. 5, pp. 5683-5689, 2012.

[99] M. R. Alison, R. Poulsom, R. Jeffery et al., "Hepatocytes from non-hepatic adult stem cells," Nature, vol. 406, no. 6793, p. 257, 2000.

[100] H. Kanazawa, Y. Fujimoto, T. Teratani et al., "Bone marrowderived mesenchymal stem cells ameliorate hepatic ischemia reperfusion injury in a rat model," PLoS ONE, vol. 6, no. 4, Article ID e19195, 2011.

[101] A. Banas, T. Teratani, Y. Yamamoto et al., "Rapid hepatic fate specification of adipose-derived stem cells and their therapeutic potential for liver failure," Journal of Gastroenterology and Hepatology, vol. 24, no. 1, pp. 70-77, 2009.

[102] B. Parekkadan, D. Van Poll, K. Suganuma et al., "Mesenchymal stem cell-derived molecules reverse fulminant hepatic failure," PLoS ONE, vol. 2, no. 9, article e941, 2007.

[103] M. Mohamadnejad, M. Namiri, M. Bagheri et al., "Phase 1 human trial of autologous bone marrow-hematopoietic stem cell transplantation in patients with decompensated cirrhosis," World Journal of Gastroenterology, vol. 13, no. 24, pp. 3359-3363, 2007.

[104] C. Toma, M. F. Pittenger, K. S. Cahill, B. J. Byrne, and P. D. Kessler, "Human mesenchymal stem cells differentiate to a cardiomyocyte phenotype in the adult murine heart," Circulation, vol. 105, no. 1, pp. 93-98, 2002.

[105] X. Li, X. Yu, Q. Lin et al., "Bone marrow mesenchymal stem cells differentiate into functional cardiac phenotypes by cardiac microenvironment," Journal of Molecular and Cellular Cardiology, vol. 42, no. 2, pp. 295-303, 2007.

[106] T. Wang, Z. Xu, W. Jiang, and A. Ma, "Cell-to-cell contact induces mesenchymal stem cell to differentiate into cardiomyocyte and smooth muscle cell," International Journal of Cardiology, vol. 109, no. 1, pp. 74-81, 2006.

[107] S. Makino, K. Fukuda, S. Miyoshi et al., "Cardiomyocytes can be generated from marrow stromal cells in vitro," Journal of Clinical Investigation, vol. 103, no. 5, pp. 697-705, 1999.

[108] M. Xu, M. Wani, Y.-S. Dai et al., "Differentiation of bone marrow stromal cells into the cardiac phenotype requires intercellular communication with myocytes," Circulation, vol. 110, no. 17, pp. 2658-2665, 2004.

[109] H. Hamamoto, J. H. Gorman III, L. P. Ryan et al., "Allogeneic mesenchymal precursor cell therapy to limit remodeling after myocardial infarction: the effect of cell dosage," Annals of Thoracic Surgery, vol. 87, no. 3, pp. 794-801, 2009.

[110] K. H. Schuleri, G. S. Feigenbaum, M. Centola et al., "Autologous mesenchymal stem cells produce reverse remodelling in chronic ischaemic cardiomyopathy," European Heart Journal, vol. 30, no. 22, pp. 2722-2732, 2009.

[111] J. A. Dixon, R. C. Gorman, R. E. Stroud et al., "Mesenchymal cell transplantation and myocardial remodeling after myocardial infarction," Circulation, vol. 120, no. 1, pp. S220-S229, 2009.

[112] B. Trachtenberg, D. L. Velazquez, A. R. Williams et al., "Rationale and design of the transendocardial injection of autologous human cells (bone marrow or mesenchymal) in chronic ischemic left ventricular dysfunction and heart failure secondary to myocardial infarction (TAC-HFT) trial: a randomized, double-blind, placebo-controlled study of safety and efficacy," American Heart Journal, vol. 161, no. 3, pp. 487-493, 2011.

[113] S.-L. Chen, W.-W. Fang, F. Ye et al., "Effect on left ventricular function of intracoronary transplantation of autologous bone 
marrow mesenchymal stem cell in patients with acute myocardial infarction," American Journal of Cardiology, vol. 94, no. 1, pp. 92-95, 2004.

[114] J. M. Hare, J. H. Traverse, T. D. Henry et al., "A randomized, double-blind, placebo-controlled, dose-escalation study of intravenous adult human mesenchymal stem cells (prochymal) after acute myocardial infarction," Journal of the American College of Cardiology, vol. 54, no. 24, pp. 2277-2286, 2009.

[115] A. R. Williams, B. Trachtenberg, D. L. Velazquez et al., "Intramyocardial stem cell injection in patients with ischemic cardiomyopathy: functional recovery and reverse remodeling," Circulation Research, vol. 108, no. 7, pp. 792-796, 2011.

[116] A. I. Caplan and J. E. Dennis, "Mesenchymal stem cells as trophic mediators," Journal of Cellular Biochemistry, vol. 98, no. 5, pp. 1076-1084, 2006.

[117] T. Kinnaird, E. S. Burnett, M. Shou et al., "Local delivery of marrow-derived stromal cells augments collateral perfusion through paracrine mechanisms," Circulation, vol. 109, no. 12, pp. 1543-1549, 2004.

[118] S. H. Ranganath, O. Levy, M. S. Inamdar, and J. M. Karp, "Harnessing the mesenchymal stem cell secretome for the treatment of cardiovascular disease," Cell Stem Cell, vol. 10, no. 3, pp. 244-258, 2012.

[119] A. Nakamura-Ishizu and T. Suda, "Hematopoietic stem cell niche: an interplay among a repertoire of multiple functional niches," Biochimica et Biophysica Acta, vol. 1830, no. 2, pp. 24042409, 2013.

[120] F. Nwajei and M. Konopleva, "The bone marrow microenvironment as niche retreats for hematopoietic and leukemic stem cells," Advances in Hematology, vol. 2013, Article ID 953982, 8 pages, 2013.

[121] H. Yagi, B. Parekkadan, K. Suganuma et al., "Long-term superior performance of a stem cell/hepatocyte device for the treatment of acute liver failure," Tissue Engineering Part A, vol. 15, no. 11, pp. 3377-3388, 2009.

[122] A. Banas, T. Teratani, Y. Yamamoto et al., "IFATS collection: in vivo therapeutic potential of human adipose tissue mesenchymal stem cells after transplantation into mice with liver injury," Stem Cells, vol. 26, no. 10, pp. 2705-2712, 2008.

[123] K. Le Blanc and O. Ringdén, "Immunomodulation by mesenchymal stem cells and clinical experience," Journal of Internal Medicine, vol. 262, no. 5, pp. 509-525, 2007.

[124] M. Gnecchi, H. He, N. Noiseux et al., "Evidence supporting paracrine hypothesis for Akt-modified mesenchymal stem cellmediated cardiac protection and functional improvement," FASEB Journal, vol. 20, no. 6, pp. 661-669, 2006.

[125] M. Gnecchi, Z. Zhang, A. Ni, and V. J. Dzau, "Paracrine mechanisms in adult stem cell signaling and therapy," Circulation Research, vol. 103, no. 11, pp. 1204-1219, 2008.

[126] M. Gnecchi, H. He, O. D. Liang et al., "Paracrine action accounts for marked protection of ischemic heart by Akt-modified mesenchymal stem cells," Nature Medicine, vol. 11, no. 4, pp. 367-368, 2005.

[127] S. A. Glynn, M. P. Busch, R. Y. Dodd et al., "Emerging infectious agents and the nation's blood supply: responding to potential threats in the 21st century," Transfusion, vol. 53, no. 2, pp. 438454, 2013.

[128] M. Bláha, P. Mericka, V. Stepánová et al., "Prevention of infection transmission during stem cell transplantation," Folia Microbiologica, vol. 51, no. 6, pp. 609-613, 2006.
[129] Y. Mishima and M. Lotz, "Chemotaxis of human articular chondrocytes and mesenchymal stem cells," Journal of Orthopaedic Research, vol. 26, no. 10, pp. 1407-1412, 2008.

[130] J. A. Wood, D. J. Chung, S. A. Park et al., "Periocular and intraarticular injection of canine adipose-derived mesenchymal stem cells: an in vivo imaging and migration study," Journal of Ocular Pharmacology and Therapeutics, vol. 28, no. 3, pp. 307317, 2012.

[131] P. Perrot, D. Heymann, C. Charrier, S. Couillaud, F. Rédini, and F. Duteille, "Extraosseous bone formation obtained by association of mesenchymal stem cells with a periosteal flap in the rat," Annals of Plastic Surgery, vol. 59, no. 2, pp. 201-206, 2007.

[132] K. Pelttari, A. Winter, E. Steck et al., "Premature induction of hypertrophy during in vitro chondrogenesis of human mesenchymal stem cells correlates with calcification and vascular invasion after ectopic transplantation in SCID mice," Arthritis and Rheumatism, vol. 54, no. 10, pp. 3254-3266, 2006.

[133] M. Breitbach, T. Bostani, W. Roell et al., "Potential risks of bone marrow cell transplantation into infarcted hearts," Blood, vol. 110, no. 4, pp. 1362-1369, 2007.

[134] R. Lis, C. Touboul, P. Mirshahi et al., "Tumor associated mesenchymal stem cells protects ovarian cancer cells from hyperthermia through CXCL12," International Journal of Cancer, vol. 128, no. 3, pp. 715-725, 2011.

[135] R. Lis, C. Touboul, C. M. Raynaud et al., "Mesenchymal cell interaction with ovarian cancer cells triggers pro-metastatic properties," PLoS ONE, vol. 7, no. 5, Article ID e38340, 2012.

[136] L. Sensebé, K. Tarte, J. Galipeau et al., "Limited acquisition of chromosomal aberrations in human adult mesenchymal stromal cells," Cell Stem Cell, vol. 10, no. 1, pp. 9-10, 2012.

[137] U. Ben-David, Y. Mayshar, and N. Benvenisty, "Large-scale analysis reveals acquisition of lineage-specific chromosomal aberrations in human adult stem cells," Cell Stem Cell, vol. 9, no. 2, pp. 97-102, 2011.

[138] R. Tasso, A. Augello, M. Carida' et al., "Development of sarcomas in mice implanted with mesenchymal stem cells seeded onto bioscaffolds," Carcinogenesis, vol. 30, no. 1, pp. 150-157, 2009. 

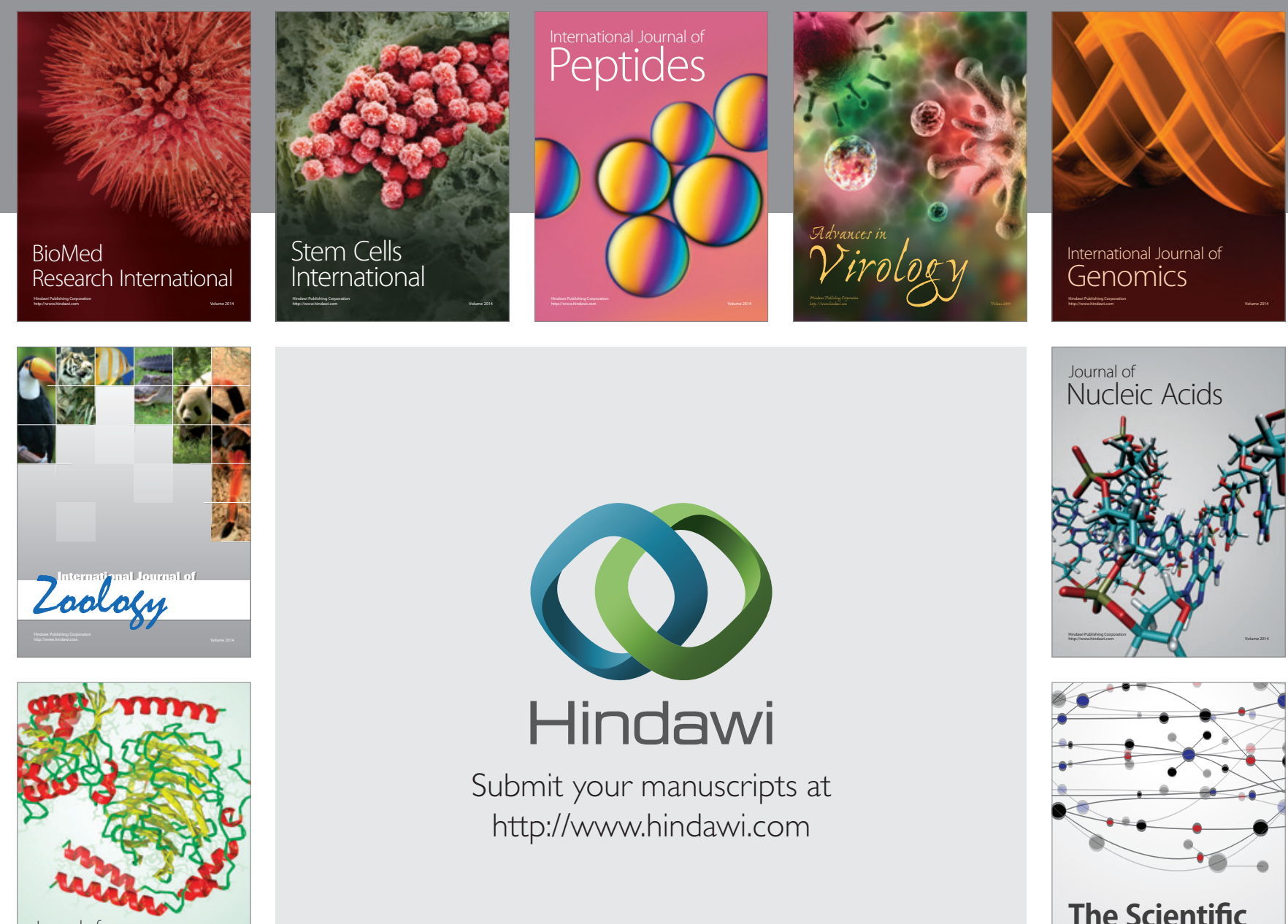

Submit your manuscripts at

http://www.hindawi.com

Journal of
Signal Transduction
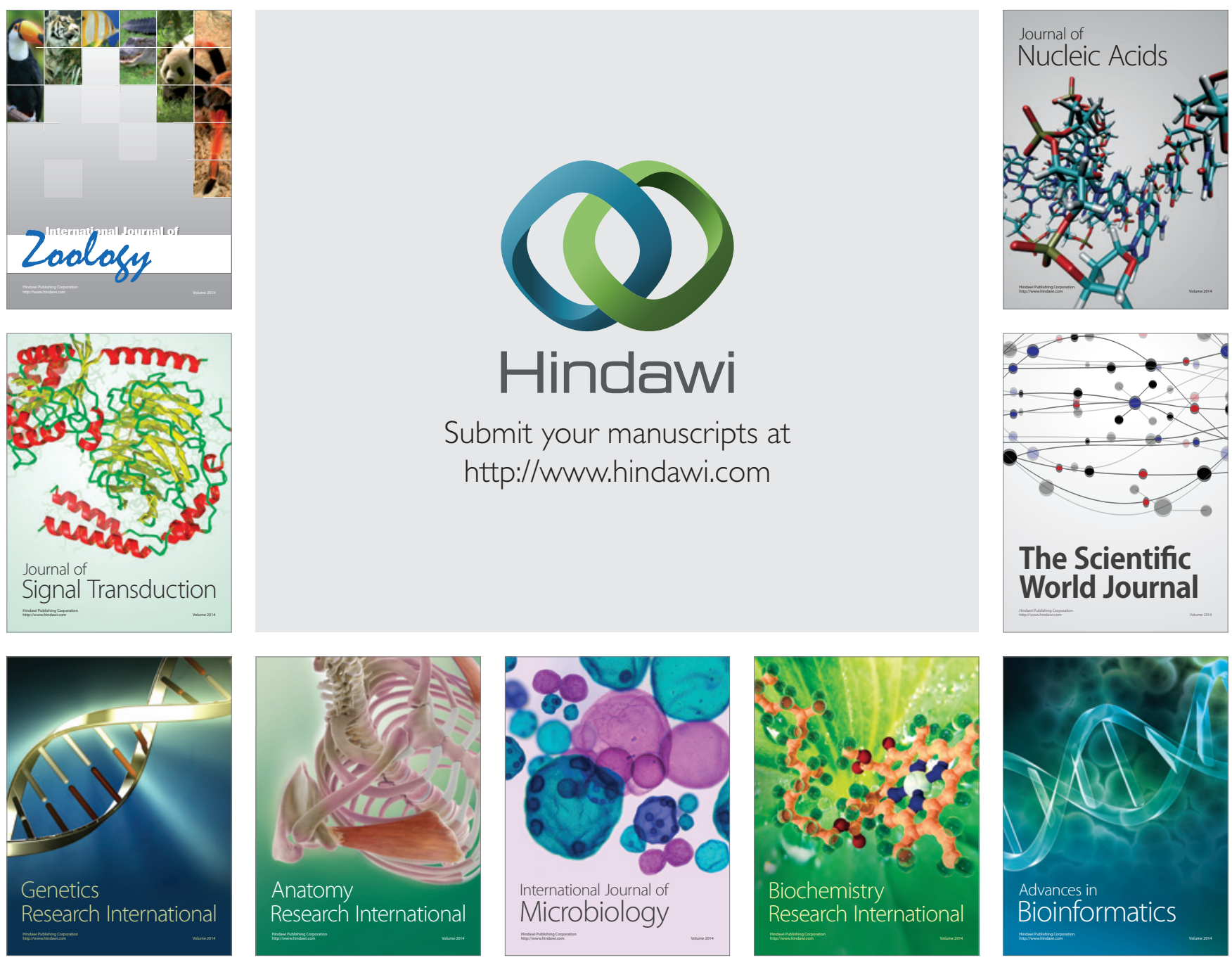

The Scientific World Journal
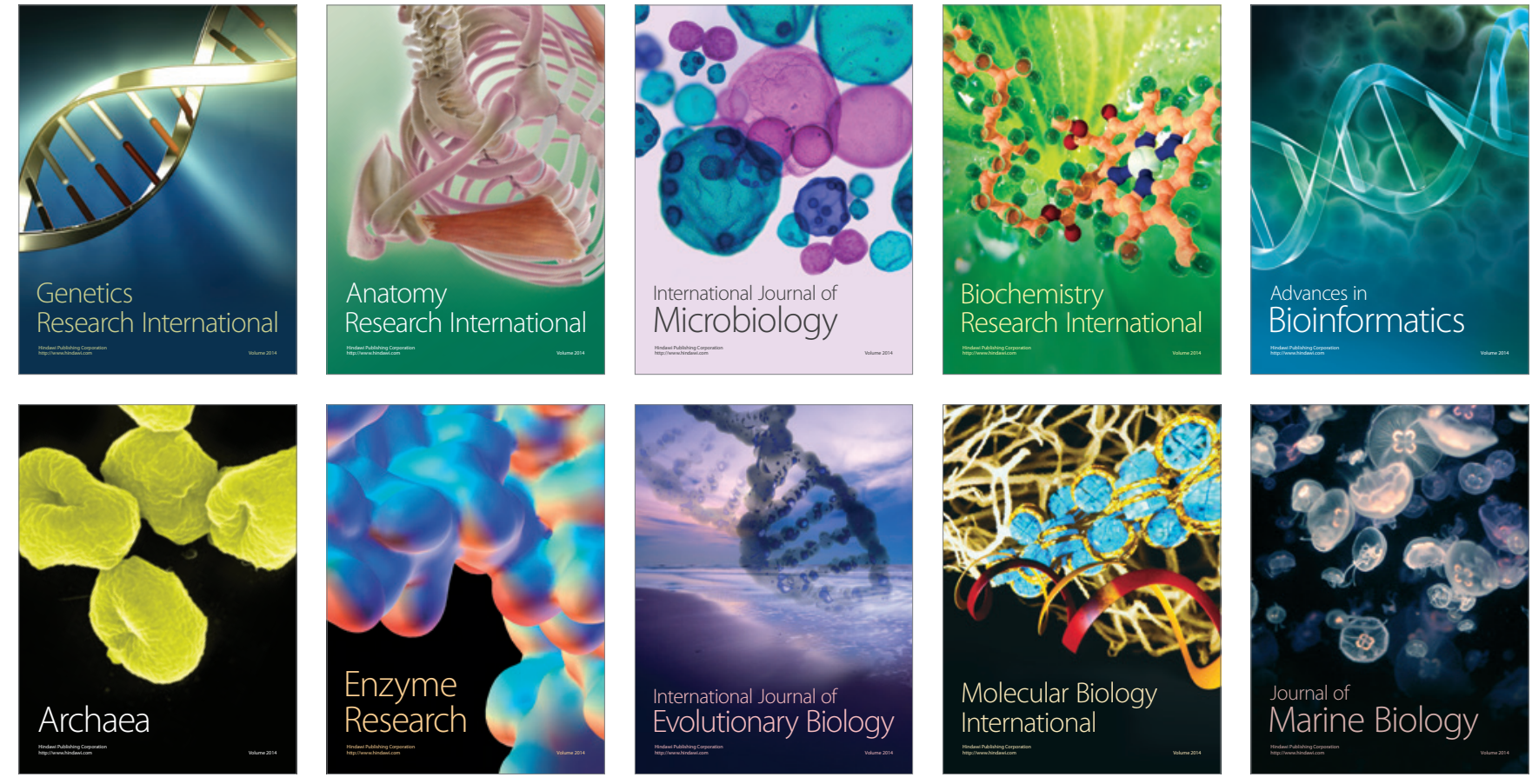